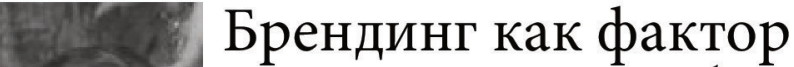 конкурентоспособности киностудии «Ленфильм»
}

\section{М.И. Панкратова}

В статье рассматривается современное состояние старейшей российской киностудии "Ленфильм", оцениваются ее конкурентные преимущества, определяются тендениии развития. Анализ позволяет сбормулировать первоочередные организаиионные меры, направленные на развитие и возвращение "Ленбильма" на позииию одной из ведущих киностудий России.

\section{фильмопроизвод-} ство, киностудия, «Ленфильм», конкурентоспособность, совершенствование деятельности

1 «Киноиндустрия российской федерации". Исследование компании «Невафильм» при участии "Movie Research” («Универс Консалтинг) и "iks-Consulting" для Европейской аудиовизуальной обсерватории. Декабрь. 2014 // NEVAFILM.RU// URL: www.nevafilm.ru/ index.html (дата обращения: 27.05.2015).
$\Phi$ инансовая устойчивость любой организации, как показывает мировой опыт, на 90\% зависит от уровня менеджмента (умения сформировать бизнес-модель, сформулировать стратегию бизнеса) и только на $10 \%$ от воздействия внешних факторов экономической среды. Данный критерий определяет и современное состояние фильмопроизводства, которое характеризуется жесткой конкуренцией. Создание и внедрение новых видов кинематографа, развитие производственного сервиса заставляют участников российского рынка кинопроизводства пересматривать бизнес-модели и перепрофилировать деятельность. Основными проблемами российской отрасли сегодня попрежнему остаются устаревающая кинопроизводственная база государственных киностудий и переориентация крупных киностудийных комплексов с большим количеством павильонов на производство телевизионного контента. За исключением «Мосфильма", государственные киностудии нуждаются в модернизации и современной организации бизнес-процессов ${ }^{1}$. В сложившихся условиях конкурентоспособность - один из решающих факторов коммерческого успеха киностудии.

В настоящее время существуют различные подходы к пониманию сущности конкурентоспособности организаций. Рекомендации ведущих отечественных и зарубежных специалистов в области маркетинга в основном отражают вопросы повышения конкурентных преимуществ в базовых отраслях экономики. Но в России такие отрасли экономики, как “культура и искусство», «образование», не относятся к базовым, вследствие чего конку- 
${ }^{2}$ Портер М. Конкурентное преимуще ство. Как достичь высокого результата и обеспечить его устойчивость. М.: Альпина Бизнес Букс, 2008. C. 654.

${ }^{3}$ Азоев Г.Л. Конкурентные преимущества фирмы. М.: Типография «Новости», 2000. C. 255.

${ }^{4}$ Огурчиков П.К.

Мастерство продюсера кино и телевидения. М.: ЮНИТИ-ДАНА, 2008. С. 863.

${ }^{5}$ Там же.

${ }^{6}$ Там же. рентоспособность кинопредприятий и факторы, влияющие на нее, изучены не в полной мере. В научных трудах специалистов аудиовизуальной сферы, уделяющих значительное внимание вопросам производства и маркетинга данной продукции, проблема повышения конкурентоспособности организаций кинематографии также не разработана и не освещена в полной мере. В связи с этим целесообразно обратиться к понятию «конкурентоспособность» в публикациях отечественных и зарубежных авторов, пишущих о проблемах международного менеджмента и маркетинга.

Применительно к фильмопроизводству, конкурентоспособность, согласно М. Портеру, достигается кинематографическими организациями через лидерство в издержках при создании аудиовизуального произведения или дифференциации производственных услуг ${ }^{2}$. Однако Г.Л. Азоев трактует конкурентоспособность - как «экономический процесс взаимодействия, взаимосвязи и борьбы между предприятиями в целях обеспечения удовлетворения разнообразных потребностей покупателей» ${ }^{3}$. Следовательно, необходимость повышения конкурентоспособности кинопредприятий продиктована ростом роли и развитием производственного сервиса с целью обеспечения удовлетворения разнообразных потребностей пользователей киноуслуг.

Основой коммерческого успеха государственных киностудий является, как известно, достижение устойчивых конкурентных преимуществ. Решению проблемы превращения киностудий в современные киностудийные комплексы в значительной степени способствует использование брендинга - «процесса создания, развития и последующего закрепления положительного имиджа киностудии в сознании целевой аудитории» ${ }^{4}$ В этом контексте киностудия выступает в качестве артбренда, понимаемого как «сложившийся в сознании существующего или потенциального зрителя образ или эмоции, в которых выражается опыт взаимодействия с личностью или организацией путем потребления ее зрелищ» ${ }^{5}$. Согласно голливудской практике, успешному продвижению фильма способствуют четыре основных бренда: актерский, режиссерский, бренд сети демонстрации или канала вещания и студии производителяб. Это означает, что брендинг способствует не только повышению доходности киностудии (за счет повышения конкурентоспособности и снижения ее трансакционных издержек), но и обеспечивает рост конкурентоспособности кинопроектов ее собственного производства. 
${ }^{7}$ Официальный сайт киностудии "Ленфильм" // LENFILM.RU // URL: http://www.lenfilm. ru (дата обращения: $30.05 .2015)$.

\section{Мероприятия по брендингу киностудии «Ленфильм»}

Рассмотрим подробнее мероприятия по брендингу на примере одной из крупнейших киностудий страны - ОАО «Ленфильм», основанной в 1914 году ${ }^{7}$. За вековую историю на ее базе было поставлено около 1500 фильмов для кино и телевидения. Многие из них вошли в Золотой фонд отечественного кино, награждены

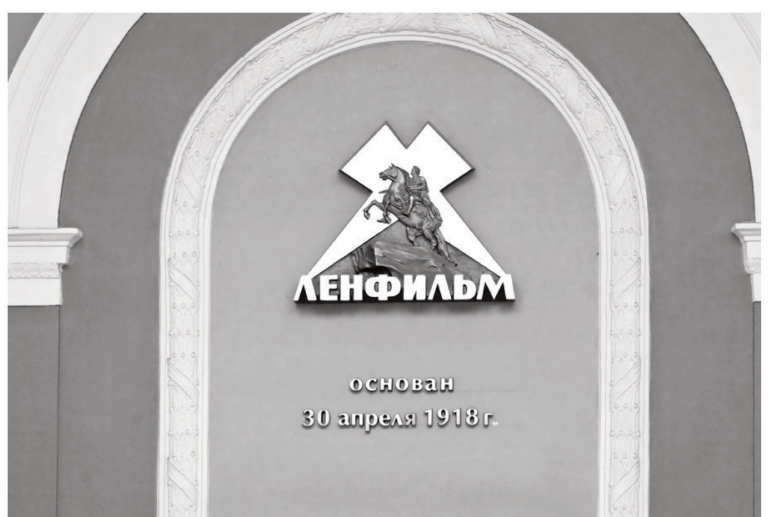
премиями Международных кинофестивалей, дублировались на языках зарубежных стран.

В последние годы киностудия переживала не лучшие времена. Согласно документам, ее текущее состояние оценивается низкой мобильностью имущества компании (мобильные средства составляют 11\%, иммобилизованные ак-

Киностудия "Ленфильм". Дата основания «Ленфильма» приводится по книге А. Позднякова «Листья аканта. История и предыстория “Ленфильма' 1914-2014” тивы - 89\%), а в структуре оборотных средств основную долю занимает дебиторская задолженность; высокими темпами увеличивается и доля отложенных налоговых активов, в итоге повышение мобильности активов требует дополнительно минимум 120 млн.. рублей ликвидных средств.

Выявленные в деятельности ОАО «Ленфильм» проблемы характерны для большей части государственных кинокомпаний: с одной стороны, в распоряжении этих киностудий имеется многолетний накопленный опыт, реквизит, декорации, костюмы, обширные территории, традиции, то есть все то, что в совокупности относится к бренду, с другой - обнаруживаются финансовые проблемы, связанные с крайне малой долей мобильных средств в активах.

В 2012-2013 годы Правительство РФ предприняло попытки реорганизовать «Ленфильм», которые пока не привели к ее превращению в современный киностудийный комплекс, но позволили вернуть ей прежние производственные функции, актуализировать ее имидж. Тем не менее перед руководством «Ленфильма» по-прежнему стоит серьезная задача - вернуть киностудию на позиции одной из ведущих российских киноорганизаций и вывести бренд «Ленфильм» на мировой уровень. Иными словами, это должна быть современная и технически оснащенная инфраструктура, обладающая креативным и квалифицированным персоналом, которая сможет выпускать в год 
${ }^{8}$ Огурчиков П.К. Управление рисками в отечественном кинобизнесе // Вестник университета (ГУу) 2013, № 2. C. $77-84$. не менее 15-ти кинопроектов и 4-х телесериалов. Данные показатели, как свидетельствует практика, приобретают в долгосрочной перспективе все большее значение в работе киностудий и продюсерских компаний ${ }^{8}$. Однако реализация этих задач требует серьезных преобразований, прежде всего организационных.

К первостепенным оперативным мерам, направленным на повышение конкурентоспособности киностудии, следует отнести: создание студийного комплекса, отвечающего современным требованиям киноиндустрии, развитие кинобизнеса, повышение роли киностудии в культурной и туристической жизни СанктПетербурга. Рассмотрим их более подробно.

Создание студийного комплекса может осуществляться как за счет модернизации уже имеющегося парка производственных мощностей, так и в результате развития производственного сервиса. Пока же кинопроизводственная цепочка у «Ленфильма» является неполной, в связи с чем необходимо восстановление/ обновление ее составляющих, возврат утраченных киностудией производственных функций.

Развитие производственного сервиса предполагает решение цикла задач по ведущим направлениям:

- предоставление полного комплекса как кинопроизводственных услуг, так и технического оборудования съемочным группам;

- формирование системы объектов социальной инфраструктуры для продюсеров и членов их команд путем заключения договоров с гостиницами, медицинскими учреждениями, иными видами учреждений сферы социальных услуг.

Развитие кинобизнеса тесно связано с созданием Продюсерского центра, цель которого состоит в выведении производственного цикла «Ленфильма» на качественно новый уровень, а также в реализации творческих проектов в сфере кинопроизводства. Направленность деятельности такого центра с учетом организационных преобразований в области продюсирования концентрируется на таких задачах, как инициирование проектов, поиск инвесторов, формирование съемочных групп, подбор актеров и массовки, отбор, оценка и доработка сценариев, постоянное проведение мониторинга кинорынка, изучение зрительских предпочтений, обеспечение прав на кинопродукцию, включая права на прокат, телепоказ, выпуск видео, компьютерные игры и т. д. Все эти факторы обеспечивают признаки брендовой продукции "Ленфильма", как и использование товарного знака киностудии. 
${ }^{9}$ Фотографии предоставлены ОАО «Киностудия “Ленфильм" , Прим. авт.

\section{Мероприятия по продвижению бренда "Ленфильм"}

Повышение роли киностудии в культурной и туристической жизни Санкт-Петербурга тесно связано с популяризацией ее продукта и с вхождением киностудии в культурно-музейный заповедник (кластер) в Александровском парке. Однако данное позиционирование предполагает и расширение направлений ее деятельности: проведение экскурсий; создание музея и организацию выставок, посвященных кинематографу, на основе имеющейся на «Ленфильме» коллекции реквизита и декораций; проведение образовательных семинаров и круглых столов с участием известных деятелей отечественного и зарубежного кинематографа. В результате реализации этих направлений киностудия как артбренд получает более широкие возможности для работы с конечным потребителем услуг - зрителем.

«Ленфильм» уже участвовал в общероссийских мероприятиях, таких как «Ночь в музее», шествие «Бессмертный полкСанкт-Петербург», “День Победы - 9 мая», что позволило ему

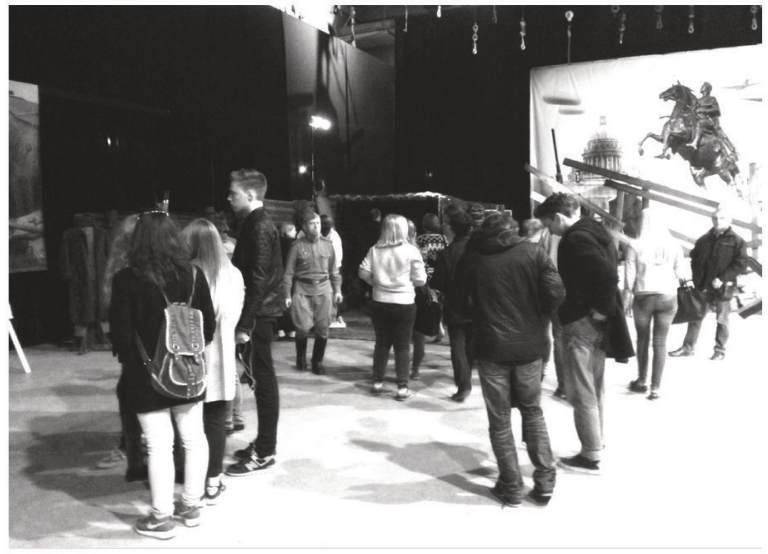

Посетители акции «Ночь в музее»
${ }^{10}$ Фотографии предоставлены ОАО «Киностудия “Ленфильм" . расширить коммуникативные связи с потенциальными зрителями. Акция «Ночь в музее» ${ }^{9}$ в честь 70-летия Победы в Великой Отечественной войне была тепло встречена жителями и ветеранами города. Показ фильмов о войне, полевая кухня, возможность простых людей сфотографироваться на фоне декораций, игрового автотранспорта тех лет с сотрудниками «Ленфильма», одетыми в военную форму, - все это приносит киностудии дополнительный позитивный имидж, содействует росту ее репутации.

С целью оперативного продвижения кинопроектов Продюсерского центра «Ленфильма» на базе кинотеатра «Великан Парк» был создан музей киностудии, где прошла выставка «По ту сторону кино», состоящая из нескольких экспозиций, посвященных кинопроизводству студии. Ее посетителям представилась уникальная возможность очутиться в декорациях детской сказки «Самый рыжий лис» ${ }^{10}$ (режиссер-постановщик и автор сценария А.Н. Стреляная). Съемки этого кинопроизведения завершились на «Ленфильме» недавно, и посетители выставки 


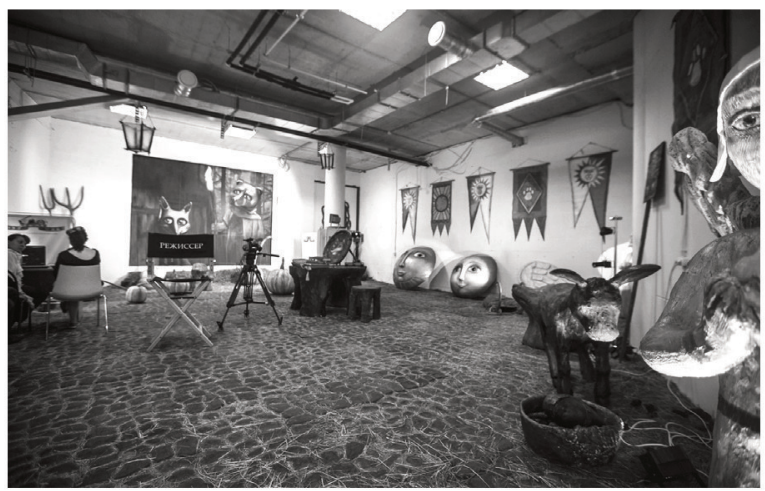

смогли воочию прочувствовать атмосферу съемки детской сказки, ощутив себя героями фильма «Сaмый рыжий лис».

Эти и иные акции маркетингового характера в деятельности киностудии играют существенную роль, обеспечивая организации конкурентное преимущество. Рассмотрим основ-

Декорации детской сказки «Самый рыжий лис» ные факторы конкурентоспособности кинопредприятия, к которым относятся:

- финансовое состояние кинопредприятия;

- доступность источников финансирования;

- наличие современного киносъемочного, звукового оборудования;

- обеспеченность высококвалифицированными кадрами;

- способность к ценовому маневрированию в предоставлении производственного сервиса;

- наличие эффективной стратегии маркетинга;

- платежеспособность основных клиентов.

При этом выделим и основные компоненты конкурентоспособности:

- технико-экономические (качество, производительность труда, издержки производства аудиовизуальной продукции);

- коммерческие (конъюктура рынка, предоставляемый сервис, реклама, имидж киностудии);

- нормативно-правовые (патентно-правовые требования, приобретение лицензий, отчуждение исключительных прав).

Чтобы оценить конкурентную среду киностудии «Ленфильм», были использованы следующие критерии конкурентоспособности с учетом сложившихся тенденций на рынке государственной киноиндустрии (таблица 1). Учитывалось три основных фактора:

1. Объем производственных услуг в полном цикле кинопроизводства.

2. Доля площади киностудии в общем объеме площади государственных киностудий.

3. Доля количества павильонов в общем количестве павильонов и доля площади павильонов в общей площади павильонов. 
Государственные киностудии и киностудии со $100 \%$ государственным акционерным капиталом

\begin{tabular}{|c|c|c|c|c|c|}
\hline $\begin{array}{l}\text { Nog } \\
\Pi / \Pi / \Pi\end{array}$ & Киностудия & $\begin{array}{l}\text { Админнстра- } \\
\text { тивный округ }\end{array}$ & $\begin{array}{c}\text { Общая } \\
\text { площадь, } \\
\text { га } \\
\end{array}$ & $\begin{array}{c}\text { Коп-во } \\
\text { павнльонов, } \\
\text { шт } \\
\end{array}$ & $\begin{array}{c}\text { Площадь } \\
\text { павильонов, } \\
\text { кв.м. } \\
\end{array}$ \\
\hline 1. & $\begin{array}{l}\text { ОАО «Западно-Снбирекая } \\
\text { киностудняв }\end{array}$ & Сиб̄ирский & н/д & 1 & - \\
\hline 2. & ОАО аКазанская студияз & Приволжекий & 0,5 & - & - \\
\hline 3. & $\begin{array}{l}\text { ОАО аКиностудия } \\
\text { Женнаучфнльм и } \\
\text { ОАО дЦентр национального } \\
\text { фильмаs }\end{array}$ & $\begin{array}{l}\text { Северо- } \\
\text { Западный }\end{array}$ & 1,9 & 7 & $\begin{array}{l}1300 \\
2100\end{array}$ \\
\hline 4 , & $\begin{array}{l}\text { ОАО иКиностудня } \\
\text { Ленфильм }\end{array}$ & $\begin{array}{c}\text { Северо- } \\
\text { Западный }\end{array}$ & 23 & 5 & 3500 \\
\hline 5 & $\begin{array}{l}\text { ОАО аНижне-Вольская } \\
\text { студия кинохроникия }\end{array}$ & Привопжский & н/д & 1 & - \\
\hline 6. & $\begin{array}{l}\text { ОАО иСвердловская } \\
\text { киностудняв }\end{array}$ & Уральский & 2 & 1 & 700 \\
\hline 7. & $\begin{array}{l}\text { ОАО аСеверо-Кавказкая } \\
\text { студия кинохроникия }\end{array}$ & ЮОжный & 0,5 & $=$ & - \\
\hline 8. & $\begin{array}{l}\text { ОАО жТПО иСанкт- } \\
\text { Петербургская студия } \\
\text { документальных фильмов }\end{array}$ & $\begin{array}{l}\text { Северо- } \\
\text { Западный }\end{array}$ & н/д & 2 & н/д \\
\hline 9. & $\begin{array}{l}\text { ОАО жТПО аЦентральная } \\
\text { киностудня детских и } \\
\text { юношеских фнльмов имени } \\
\text { М. Горькогов }\end{array}$ & Центральный & 3,2 & 5 & 3200 \\
\hline 10. & $\begin{array}{l}\text { ФГУП акиноконцерн } \\
\text { Мосфильмs }\end{array}$ & Центральный & 34,7 & 12 & 11000 \\
\hline 11. & $\begin{array}{l}\text { ФГУП кТПО } \\
\text { АДальневосточная ордена } \\
\text { Знак Почетам студия } \\
\text { кинохроникия }\end{array}$ & $\begin{array}{c}\text { Дальне- } \\
\text { восточный }\end{array}$ & - & - & - \\
\hline 12 & $\begin{array}{l}\text { ФГУП «ТПО аКиностудия } \\
\text { АСоюммультфильмь }\end{array}$ & Центральный & - & - & - \\
\hline 13. & $\begin{array}{l}\text { ГП «Российская центральная } \\
\text { киновидеостудия } \\
\text { хроникально- } \\
\text { документальных и учебных } \\
\text { фильмовэ }\end{array}$ & Центральный & - & - & - \\
\hline
\end{tabular}

Характеристику же основных игроков рынка кинопроизводственных услуг можно представить в виде рисунка 1.

В итоге проведенное исследование показало, что среди государственных киностудий «Ленфильм» занимает:

- второе место по размеру площади в России;

- второе место по площади павильонов;

- третье место по количеству павильонов.

По объему производственных услуг в полном цикле кинопроизводства основными конкурентами «Ленфильма» (таблица 2) явля- 


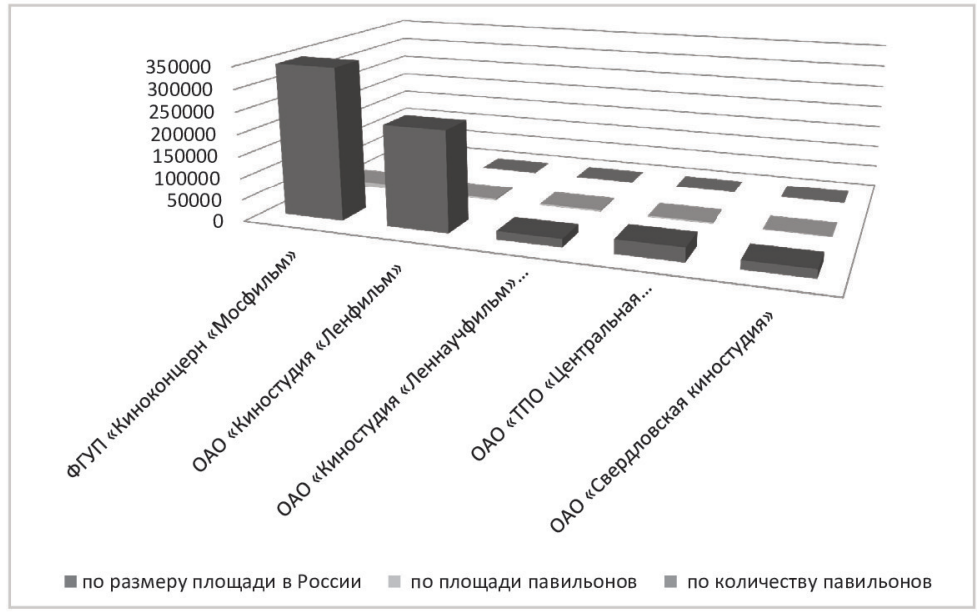

Рис. 1. Основные игроки рынка кинопроизводственных услуг

ются киностудия “RWS” и киносервисные компании, не имеющие собственных съемочных павильонов, но активно предоставляющие в аренду киносъемочное, операторское, осветительное и звуковое оборудование. "Студия ВЕК», расположенная в СанктПетербурге, также предоставляет в аренду специализированный транспорт (гримвагены, светобазы с генераторами, камервагены).

Таблица 2

Ассортимент услуг российских киносервисных компаний и киностудийных

комплексов (г.Санкт-Петербург)

\begin{tabular}{|c|c|c|c|c|c|c|c|c|c|c|c|c|}
\hline \multirow[b]{2}{*}{ 各 } & \multirow[b]{2}{*}{$\begin{array}{l}\text { Сервисная } \\
\text { компания }\end{array}$} & \multicolumn{5}{|c|}{ Съемочный период } & \multicolumn{5}{|c|}{$\begin{array}{l}\text { Монтажно-тонировочный } \\
\text { период }\end{array}$} & \multirow[b]{2}{*}{ 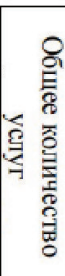 } \\
\hline & & 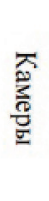 & 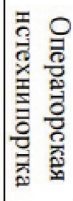 & $\underset{\Im}{\mathscr{Q}}$ & $\underset{\text { w }}{w}$ & 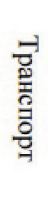 & 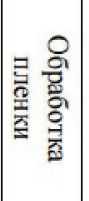 & $\begin{array}{l}\frac{2}{9} \\
\frac{1}{1} \\
\frac{1}{x}\end{array}$ & 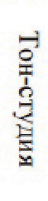 & 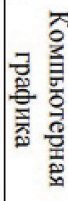 & 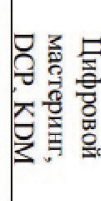 & \\
\hline 1 & «RWS $»$ & + & + & + & + & + & & + & + & + & + & 9 \\
\hline 2 & «енфильм» & + & + & + & + & + & & + & + & + & & 8 \\
\hline 3 & $\begin{array}{l}\text { «Студия } \\
\text { ВЕК» }\end{array}$ & + & + & + & & + & & + & + & + & & 7 \\
\hline 4 & «G-BRO» & + & + & + & & & & + & & + & & 5 \\
\hline 5 & $\langle\mathrm{HHG}\rangle$ & + & & + & & & & + & & & & 3 \\
\hline 6 & "ACT $\rangle$ & + & + & + & & & & & & & & 3 \\
\hline 7 & «Невафильм» & & & & & & & & + & & + & 2 \\
\hline 8 & $\begin{array}{l}\text { «Миди } \\
\text { Синема» } \\
\text { («Мельница») }\end{array}$ & & & & & & & & + & + & & 2 \\
\hline 9 & «ProDigi» & & & & & & & & & & + & 1 \\
\hline
\end{tabular}




\author{
${ }^{11}$ Панкратова М.И. \\ Организационные \\ преобразования как \\ фактор совершен- \\ ствования деятельно- \\ сти киностудии «Лен- \\ фильм" // Вестник \\ университета (ГУу), \\ 2015, № 1. C. 45-51.
}

Таким образом, на основании проведенного анализа можно сделать вывод, что конкурентоспособность является не просто оценочным показателем, а это скорее философия методологии работы организаций кинематографии в условиях жесткой конкуренции, что требует дальнейших исследований.

Превращению киностудии «Ленфильм» в современный киностудийный комплекс в значительной степени будет способствовать не только совершенствование организационно-экономического механизма, но и использование брендинга, что, безусловно, приведет к повышению доходности работы ОАО «Ленфильм» за счет увеличения функциональной нагрузки на компанию и полной загрузки ее мощностей, активизации процесса основной деятельности с целью производства и выпуска высококачественной и высоко конкурентной кинопродукции ${ }^{11}$.

\section{ЛИТЕРАТУРА}

4. Азоев Г.Л. Конкурентные преимущества фирмы / Г.Л. Азоев, А.П. Челенков. М.: Типография «Новости», 2000. -255 c.

5. Восколович Н.А., Молчанов И.Н. Социально-экономические аспекты формирования зрительской киноаудитории // Вестник ВГИК, 2012, № 14. - С. 109-118.

6. Молчанов И.Н., Молчанова Н.П. К вопросу о модернизации государственного регулирования в сфере культуры // Вестник ВГИК, 2012, № 14. - С. 80-87.

7. Огурчиков П.К. Управление рисками в отечественном кинобизнесе // Вестник университета (ГУУ), 2013, № 2. - С. 77-84.

8. Панкратова М.И. Организационные преобразования как фактор совершенствования деятельности киностудии “Ленфильм» // Вестник университета (ГУУ), 2015, № 1. C. 45-51.

\section{REFERENCES}

1. Azoev G.L. Konkurentnye preimushchestva firmy [Competitive advantages of the company] / G.L. Azoev, A.P. Chelenkov. - M: Tipografia «Novosti», 2000. - 255 p.

2. Voskolovich N.A., Molchanov I.N. Sotsialno-ekonomicheskie aspecty formirovania zritelskoy kinoauditorii [Socio-economic aspects of formation of the viewing film audience] // N.A. Voskolovich, I.N. Molchanov // Vestnik VGIK, 2012, № 14. - P. 109-118.

3. Molchanov I.N., Molchanova N.P. K voprosu o modernizatsii gosudarstvennogo regulirovania $v$ sfere kultury [To a question of state regulation in the area of culture] // Vestnik VGIK, 2012, № 14.- P. 80-87.

4. Ogurchikov P.K. Upravlenie riskami votechestvennom kinobiznese [Risk management in the domestic film business] // Vestnik universiteta (GUU), 2013, № 2. - P. 77-84.

5. Pankratova M.I. Organizatsionnye preobrazovania kak factor sovershenstvovania deatelnost $i$ kinostudii "Lenfilm» [Organizational transformation as a factor of improving activity the «Lenfilm» studio] // Vestnik universiteta (GUU), 2015, № 1. - P. 45-51. 


\title{
Branding as a Factor of Competitiveness of the "Lenfilm" Studio
}

\author{
Marina I. Pankratova \\ Post-graduate \\ UDC 778.58:658+778.58“Ленфильм»
}

\begin{abstract}
The current state of filmmaking is characterized by tough competition. Creation and implementation of new types of cinema, development of production service caused participants of the domestic production review the business model and restructure activities. Up to date the main problems of the industry remain extremely scanty film production base of state film studios. Major film studios repurpose activity to the production of television content. With the exception of "Mosfilm", the state film studios require modernization and the modern organization of business processes.

Problems of production and marketing of audiovisual products have not been effectively studied by experts in the audiovisual field, as well as the problem of modernization of cinema production through competiveness has not been sufficiently rationalized and elucidated. Thus the value of the article consists in development of proposals aimed at improving the competitiveness of the state film studios.
\end{abstract}

Summing up, high priorities measures in order to converse «Lenfilm» into a modern aggregate of facilities basing on rationalization of the organizational as well as an economic mechanism and use of branding are advanced. These measures will give rise of the studio's profitability due to functional load on the company, the full load capacity. It will help reach the main aim - high-quality and highly competitive film production.

KEY WORDS: film production, film studio, "Lenfilm", competitiveness, improvement activities 